\title{
POTRET KESEJAHTERAAN RAKYAT DI PROVINSI BALI MENGGUNAKAN METODE CHERNOFF FACES
}

\author{
I WAYAN Widhi Dirgantara ${ }^{1}$, KOMANG Gde SuKarsa ${ }^{2}$, \\ KOMANG DHARMAWAN ${ }^{3}$ \\ 1, 2, 3 Jurusan Matematika FMIPA Universitas Udayana, Bukit Jimbaran-Bali, \\ e-mail: ${ }^{1}$ widhidirgantara@gmail.com, ${ }^{2}$ sukarsakomang@yahoo.com, \\ dharmawan.komang@gmail.com
}

\begin{abstract}
Chernoff Faces method is a graphical method of visualization techniques to present data with many variables in the form of a cartoon face which can be determined by 20 parameters or less. In this research it was shown how the Chernoff Faces method was used to see welfare of the people in the province of Bali and Bali's nine regencies. To pair the variables and Chernoff's facial features, then we used Principal Component Analysis and survey to make the faces look more human. The result from 18 indicators of welfare of the people in the province of Bali, only 8 indicators were not really well. It was obtained too that Tabanan was the most prosperous regency and Karangasem was the lest prosperous regency.
\end{abstract}

Keywords: Welfare of The People, Principal Component Analysis, Chernoff Faces

\section{Pendahuluan}

Pemerintah Provinsi Bali melalui beberapa program pembangunan yang berkelanjutan terus berupaya meningkatkan kesejahteraan masyarakat. Evaluasi program pembangunan dapat dilakukan dengan melihat indikator kesejahteraan rakyat, sebagai sasaran dari berbagai program pembangunan. Informasi indikator kesejahteraan rakyat pada tahun 2011 dari Badan Pusat Statistik diperoleh dari data Susenas, Sakernas dan Sensus Penduduk 2010 [1]. Informasi indikator kesejahteraan rakyat disajikan dalam bentuk ulasan, tabel, diagram batang dan pie chart. Karena penyajian data dalam bentuk tabel, diagram batang dan pie chart tidak begitu menarik, maka digunakan metode Chernoff Faces untuk mengilustrasikan data multivariate pada dua dimensi.

Metode Chernoff Faces pertama kali diperkenalkan oleh Herman Chernoff pada tahun 1973, yaitu teknik visualisasi untuk mempresentasikan data dengan banyak variabel dalam bentuk wajah kartun yang dapat ditentukan hingga lebih dari 18 parameter [3].

Dalam penelitian ini, peneliti memperlihatkan bagaimana keadaan kesejahteraan rakyat di Provinsi Bali dan sembilan kabupaten yang ada di

${ }^{1}$ Mahasiswa Jurusan Matematika FMIPA Universitas Udayana

${ }^{2,3}$ Staf Pengajar Jurusan Matematika FMIPA Universitas Udayana 
Provinsi Bali yaitu Kabupaten Jembrana, Tabanan, Badung, Gianyar, Klungkung, Bangli, Karangasem, Buleleng dan Denpasar, dengan menggunakan metode Chernoff Faces.

\section{Metode Penelitian}

Pada penelitian ini menggunakan 18 indikator kesejahteraan rakyat oleh Badan Pusat Statistik[2] yaitu sebagai berikut: $\mathrm{X}_{1}=$ Laju pertumbuhan penduduk, $\mathrm{X}_{2}=$ Kepadatan penduduk per $\mathrm{km}^{2}, \mathrm{X}_{3}=$ Angka melek huruf $(\%), \mathrm{X}_{4}=$ Rata-rata lamanya sekolah (tahun), $\mathrm{X}_{5}=$ Angka harapan hidup (tahun), $\mathrm{X}_{6}=$ Pengeluaran per kapita (ribu rupiah), $\mathrm{X}_{7}=$ Persentase rata - rata pengeluaran untuk konsumsi makanan $(\%), \mathrm{X}_{8}=$ Persentase rumah tangga yang memiliki fasilitas air minum sendiri (\%), $\mathrm{X}_{9}=$ Persentase rumah tangga dengan jenis lantai bukan tanah (\%), $\mathrm{X}_{10}=$ Persentase rumah tangga dengan luas lantai $<20 \mathrm{~m}^{2}(\%), \mathrm{X}_{11}=$ Persentase rumah tangga dengan dinding tembok $(\%), \mathrm{X}_{12}=$ Persentase rumah tangga yang menggunakan sumber penerangan dari PLN $(\%), \mathrm{X}_{13}=$ Persentase rumah tangga dengan fasilitas Buang Air Besar (BAB) sendiri (\%), $\mathrm{X}_{14}=$ Persentase penduduk miskin (\%), $\mathrm{X}_{15}=$ Jumlah pengangguran terbuka (orang), $\mathrm{X}_{16}=$ Persentase penduduk yang mengalami keluhan kesehatan sebulan yang lalu (\%), $\mathrm{X}_{17}=$ Persentase penduduk yang mengalami keluhan kesehatan dan kegiatannya terganggu $(\%), \mathrm{X}_{18}=$ Jumlah penduduk yang bekerja (orang).

Jenis data yang digunakan adalah data sekunder yang diperoleh dari hasil Susenas, Sakernas dan Sensus Penduduk 2010. Sumber data yang lain adalah data primer yang diperoleh dengan menggunakan metode survei, yaitu penyebaran kuesioner di Jurusan Matematika FMIPA UNUD.

Dalam perancangan wajah Chernoff dilakukan dengan memasangkan antara indikator kesejahteraan rakyat dengan ciri wajah Chernoff. Langkahnya sebagai berikut :

a. Melakukan survei untuk memperingkatkan ciri wajah Chernoff.

b. Menggunakan Analisis Komponen Utama (AKU).

Hasil dari AKU diperoleh peubah baru $Y_{1}, Y_{2}, \ldots, Y_{18}$ yang merupakan kombinasi linear dari $\mathrm{X}_{\mathrm{i}}$. Langkah selanjutnya adalah mencari harga mutlak koefisien terbesar dari $X_{i}$ pada masing-masing $Y_{i}$, dengan $X_{i}$ adalah indikator kesejahteraan rakyat dan $\mathrm{Y}_{\mathrm{i}}$ adalah peringkat hasil survei terhadap ciri wajah Chernoff.

\section{Hasil dan Pembahasan}

a. Hasil Peringkat Ciri Wajah

Berdasarkan hasil survei, didapatkan peringkat ciri wajah Chernoff sebagai berikut : 1. Bentuk Mata, 2. Lebar Wajah, 3. Panjang Mulut, 4. Posisi Pusat Mulut, 5. Panjang Mulut, 6. Panjang Alis Mata, 7. Tinggi Alis Mata, 8. Bentuk Elips Bawah Wajah, 9. Kemiringan Alis Mata, 10. Jarak Antar Mata, 
11. Kemiringan Mata, 12. Kelengkungan Mulut, 13. Bentuk Elips Atas Wajah, 14. Lebar Hidung, 15. Setengah Tinggi Wajah, 16. Posisi Pupil Mata, 17. Tinggi Pusat Mata, 18. Posisi Telinga, 19. Setengah Panjang Mata, 20. Jarijari Telinga.

Karena dalam penelitian ini menggunakan 18 ciri wajah, maka 2 peringkat terbawah yaitu Setengah Panjang Mata dan Jari-jari Telinga dihilangkan.

b. Hasil Analisis Komponen Utama (AKU)

Setelah didapatkan hasil AKU, selanjutnya adalah mencari harga mutlak koefisien terbesar dari masing-masing peubah $\mathrm{Y}_{\mathrm{i}}$.

Untuk mengatasi $X_{i}$ yang memiliki pasangan lebih di $Y_{i}$ dan $X_{i}$ yang tidak mempunyai pasangan di $\mathrm{Y}_{\mathrm{i}}$, maka dapat dilakukan cara sebagai berikut :

- Untuk $X_{i}$ yang memiliki pasangan lebih di $Y_{i}$, dilihat letak $Y_{i}$-nya. Berdasarkan hasil AKU, $\mathrm{Y}_{1}$ menjadi peubah yang paling penting, begitu seterusnya hingga $\mathrm{Y}_{18}$.

- Untuk $\mathrm{X}_{\mathrm{i}}$ yang tidak memiliki pasangan di $\mathrm{Y}_{\mathrm{i}}$, langkah yang dilakukan adalah mencari koefisien terbesar berikutnya yang terdapat di masingmasing peubah $\mathrm{Y}_{\mathrm{i}}$.

Setelah melakukan proses AKU dan survei, didapatkan hasil seperti tampak pada Tabel 1 .

Tabel 1. Pasangan Ciri Wajah Chernoff dengan Indikator Kesejahteraan Rakyat

\begin{tabular}{|c|c|c|c|c|c|}
\hline Ciri Wajah & $\begin{array}{c}\text { Indikator } \\
\text { Kesejahteraan } \\
\text { Rakyat } \\
\end{array}$ & Ciri Wajah & $\begin{array}{c}\text { Indikator } \\
\text { Kesejahteraan } \\
\text { Rakyat } \\
\end{array}$ & Ciri Wajah & $\begin{array}{c}\text { Indikator } \\
\text { Kesejahteraan } \\
\text { Rakyat } \\
\end{array}$ \\
\hline $\begin{array}{l}\text { Bentuk } \\
\text { Mata } \\
\left(\mathrm{Y}_{1}\right)\end{array}$ & $\begin{array}{l}\text { Rata - rata } \\
\text { lamanya sekolah } \\
\left(\mathrm{X}_{4}\right)\end{array}$ & $\begin{array}{l}\text { Tinggi Alis } \\
\text { Mata } \\
\left(\mathrm{Y}_{7}\right)\end{array}$ & $\begin{array}{l}\text { Persentase rumah } \\
\text { tangga yang } \\
\text { menggunakan } \\
\text { sumber penerangan } \\
\text { dari PLN }\left(\mathrm{X}_{12}\right)\end{array}$ & $\begin{array}{l}\text { Bentuk Elips } \\
\text { Atas Wajah } \\
\left(\mathrm{Y}_{13}\right)\end{array}$ & $\begin{array}{l}\text { Angka melek huruf } \\
\left(\mathrm{X}_{3}\right)\end{array}$ \\
\hline $\begin{array}{l}\text { Lebar } \\
\text { Wajah } \\
\left(\mathrm{Y}_{2}\right)\end{array}$ & $\begin{array}{l}\text { Jumlah } \\
\text { pengangguran } \\
\text { terbuka } \\
\left(\mathrm{X}_{15}\right)\end{array}$ & $\begin{array}{l}\text { Bentuk } \\
\text { Elips } \\
\text { Bawah } \\
\text { Wajah }\left(\mathrm{Y}_{8}\right)\end{array}$ & $\begin{array}{l}\text { Angka harapan } \\
\text { hidup } \\
\left(\mathrm{X}_{5}\right)\end{array}$ & $\begin{array}{l}\text { Lebar Hidung } \\
\left(\mathrm{Y}_{14}\right)\end{array}$ & $\begin{array}{l}\text { Persentase } \\
\text { penduduk yang } \\
\text { mengalami keluhan } \\
\text { kesehatan sebulan } \\
\text { yang lalu }\left(\mathrm{X}_{16}\right)\end{array}$ \\
\hline $\begin{array}{l}\text { Panjang } \\
\text { Hidung } \\
\left(\mathrm{Y}_{3}\right)\end{array}$ & $\begin{array}{l}\text { Pengeluaran per } \\
\text { kapita } \\
\left(\mathrm{X}_{6}\right)\end{array}$ & $\begin{array}{l}\text { Kemiringan } \\
\text { Alis Mata } \\
\left(\mathrm{Y}_{9}\right)\end{array}$ & $\begin{array}{l}\text { Jumlah penduduk } \\
\text { yang bekerja } \\
\left(\mathrm{X}_{18}\right)\end{array}$ & $\begin{array}{l}\text { Setengah } \\
\text { Tinggi Wajah } \\
\left(\mathrm{Y}_{15}\right)\end{array}$ & $\begin{array}{l}\text { Persentase } \\
\text { penduduk miskin } \\
\left(\mathrm{X}_{14}\right)\end{array}$ \\
\hline $\begin{array}{l}\text { Posisi Pusat } \\
\text { Mulut } \\
\left(\mathrm{Y}_{4}\right)\end{array}$ & $\begin{array}{l}\text { Persentase rumah } \\
\text { tangga yang } \\
\text { memiliki fasilitas } \\
\text { air minum sendiri } \\
\left(\mathrm{X}_{8}\right)\end{array}$ & $\begin{array}{l}\text { Jarak Antar } \\
\text { Mata } \\
\left(\mathrm{Y}_{10}\right)\end{array}$ & $\begin{array}{l}\text { Persentase rumah } \\
\text { tangga dengan luas } \\
\text { lantai }<20 \mathrm{~m}^{2} \\
\left(\mathrm{X}_{10}\right)\end{array}$ & $\begin{array}{l}\text { Posisi Pupil } \\
\text { Mata } \\
\left(\mathrm{Y}_{16}\right)\end{array}$ & $\begin{array}{l}\text { Persentase rata - } \\
\text { rata pengeluaran } \\
\text { untuk konsumsi } \\
\text { makanan } \\
\left(\mathrm{X}_{7}\right)\end{array}$ \\
\hline $\begin{array}{l}\text { Panjang } \\
\text { Mulut } \\
\left(\mathrm{Y}_{5}\right)\end{array}$ & $\begin{array}{l}\text { Persentase rumah } \\
\text { tangga dengan } \\
\text { dinding tembok } \\
\left(\mathrm{X}_{11}\right)\end{array}$ & $\begin{array}{l}\text { Kemiringan } \\
\text { Mata } \\
\left(\mathrm{Y}_{11}\right)\end{array}$ & $\begin{array}{l}\text { Persentase rumah } \\
\text { tangga dengan } \\
\text { fasilitas Buang Air } \\
\text { Besar (BAB) } \\
\text { sendiri }\left(\mathrm{X}_{13}\right)\end{array}$ & $\begin{array}{l}\text { Tinggi Pusat } \\
\text { Mata } \\
\left(\mathrm{Y}_{17}\right)\end{array}$ & $\begin{array}{l}\text { Laju pertumbuhan } \\
\text { penduduk } \\
\left(\mathrm{X}_{1}\right)\end{array}$ \\
\hline $\begin{array}{l}\text { Panjang } \\
\text { Alis Mata } \\
\left(\mathrm{Y}_{6}\right)\end{array}$ & $\begin{array}{l}\text { Persentase } \\
\text { penduduk yang } \\
\text { mengalami } \\
\text { keluhan kesehatan } \\
\text { dan kegiatannya } \\
\text { terganggu }\left(\mathrm{X}_{17}\right)\end{array}$ & $\begin{array}{l}\text { Kelengkung } \\
\text {-an Mulut } \\
\left(\mathrm{Y}_{12}\right)\end{array}$ & $\begin{array}{l}\text { Persentase rumah } \\
\text { tangga dengan jenis } \\
\text { lantai bukan tanah } \\
\left(\mathrm{X}_{9}\right)\end{array}$ & $\begin{array}{l}\text { Posisi Telinga } \\
\left(\mathrm{Y}_{18}\right)\end{array}$ & $\begin{array}{l}\text { Kepadatan } \\
\text { penduduk per } \mathrm{km}^{2} \\
\left(\mathrm{X}_{2}\right)\end{array}$ \\
\hline
\end{tabular}


Langkah selanjutnya adalah membagi sifat ciri wajah menjadi ciri wajah positif dan negatif. Pembagian sifat ciri wajah dilakukan berdasarkan ilmu membaca wajah ${ }^{[4]}$. Selain itu dilakukan juga pembagian sifat indikator kesejahteraan rakyat menjadi sifat indikator kesejahteraan rakyat positif dan negatif. Ini bertujuan untuk membuat wajah Chernoff yang benar.

Interpretasi untuk masing-masing ciri wajah Chernoff adalah seperti tampak pada Tabel 2.

\section{Tabel 2. Interpretasi Wajah Chernoff}

\begin{tabular}{|c|c|c|c|}
\hline Ciri Wajah & Interpretasi & Ciri Wajah & Interpretasi \\
\hline Bentuk Mata & $\begin{array}{l}\text { Semakin bulat bentuk maka } \\
\text { semakin besar rata-rata lamanya } \\
\text { sekolah }\end{array}$ & $\begin{array}{l}\text { Jarak Antar } \\
\text { Mata }\end{array}$ & $\begin{array}{l}\text { Semakin besar jarak antar mata } \\
\text { maka semakin kecil presentase } \\
\text { rumah tangga dengan luas lantai } \\
<20 \mathrm{~m}^{2}\end{array}$ \\
\hline Lebar Wajah & $\begin{array}{l}\text { Semakin lebar wajah maka } \\
\text { semakin kecil jumlah } \\
\text { pengangguran terbuka }\end{array}$ & $\begin{array}{l}\text { Kemiringan } \\
\text { Mata }\end{array}$ & $\begin{array}{l}\text { Kemiringan mata dengan slope } \\
\text { positif maka semakin besar } \\
\text { presentase rumah tangga dengan } \\
\text { fasilitas BAB sendiri }\end{array}$ \\
\hline $\begin{array}{l}\text { Panjang } \\
\text { Hidung }\end{array}$ & $\begin{array}{l}\text { Semakin panjang hidung maka } \\
\text { semakin besar pengeluaran per } \\
\text { kapita }\end{array}$ & $\begin{array}{l}\text { Kelengkungan } \\
\text { Mulut }\end{array}$ & $\begin{array}{l}\text { Semakin senyum kelengkungan } \\
\text { mulut maka semakin besar } \\
\text { presentase rumah tangga dengan } \\
\text { jenis lantai bukan tanah }\end{array}$ \\
\hline $\begin{array}{l}\text { Posisi Pusat } \\
\text { Mulut }\end{array}$ & $\begin{array}{l}\text { Semakin dekat posisi pusat } \\
\text { mulut terhadap pusat wajah } \\
\text { maka semakin banyak } \\
\text { presentase rumah tangga yang } \\
\text { memiliki fasilitas air minum } \\
\text { sendiri }\end{array}$ & $\begin{array}{l}\text { Bentuk Elips } \\
\text { Atas Wajah }\end{array}$ & $\begin{array}{l}\text { Semakin bulat bentuk elips atas } \\
\text { wajah maka semakin besar angka } \\
\text { melek huruf }\end{array}$ \\
\hline $\begin{array}{l}\text { Panjang } \\
\text { Mulut }\end{array}$ & $\begin{array}{l}\text { Semakin panjang mulut maka } \\
\text { semakin besar presentase rumah } \\
\text { tangga dengan dinding tembok }\end{array}$ & Lebar Hidung & $\begin{array}{l}\text { Semakin lebar hidung maka } \\
\text { semakin kecil presentase } \\
\text { penduduk yang mengalami } \\
\text { keluhan kesehatan sebulan yang } \\
\text { lalu }\end{array}$ \\
\hline $\begin{array}{l}\text { Panjang Alis } \\
\text { Mata }\end{array}$ & $\begin{array}{l}\text { Semakin panjang alis mata maka } \\
\text { semakin kecil presentase } \\
\text { penduduk yang mengalami } \\
\text { keluhan kesehatan dan } \\
\text { kegiatannya terganggu }\end{array}$ & $\begin{array}{l}\text { Setengah } \\
\text { Tinggi Wajah }\end{array}$ & $\begin{array}{l}\text { Semakin tinggi setengah tinggi } \\
\text { wajah maka semakin kecil } \\
\text { presentase penduduk miskin }\end{array}$ \\
\hline $\begin{array}{l}\text { Tinggi Alis } \\
\text { Mata }\end{array}$ & $\begin{array}{l}\text { Semakin tinggi alis mata maka } \\
\text { semakin besar presentase rumah } \\
\text { tangga yang menggunakan } \\
\text { sumber penerangan dari PLN }\end{array}$ & $\begin{array}{l}\text { Posisi Pupil } \\
\text { Mata }\end{array}$ & $\begin{array}{l}\text { Semakin ke kanan posisi pupil } \\
\text { mata maka semakin besar } \\
\text { presentase rata-rata pengeluaran } \\
\text { untuk konsumsi makanan }\end{array}$ \\
\hline $\begin{array}{l}\text { Bentuk Elips } \\
\text { Bawah Wajah }\end{array}$ & $\begin{array}{l}\text { Semakin tidak lancip bentuk } \\
\text { elips bawah wajah maka } \\
\text { semakin besar angka harapan } \\
\text { hidup }\end{array}$ & $\begin{array}{l}\text { Tinggi Pusat } \\
\text { Mata }\end{array}$ & $\begin{array}{l}\text { Semakin tinggi pusat mata maka } \\
\text { semakin kecil laju pertumbuhan } \\
\text { penduduk }\end{array}$ \\
\hline $\begin{array}{l}\text { Kemiringan } \\
\text { Alis Mata }\end{array}$ & $\begin{array}{l}\text { Kemiringan alis mata dengan } \\
\text { slope positif maka semakin besar } \\
\text { jumlah penduduk yang bekerja }\end{array}$ & Posisi Telinga & $\begin{array}{l}\text { Semakin tinggi posisi telinga } \\
\text { maka semakin kecil kepadatan } \\
\text { penduduk per } \mathrm{km}^{2}\end{array}$ \\
\hline
\end{tabular}

Untuk membuat wajah Chernoff, cara yang dilakukan adalah mengubah data asli dari indikator kesejahteraan rakyat menjadi nilai variabel yang berada pada jangkauan data pada program STATISTICA 7.

Untuk melihat tingkat kesejahteraan Provinsi Bali secara keseluruhan, dilakukan perbandingan antara wajah Chernoff Provinsi Bali dengan wajah Chernoff ideal. Wajah Chernoff Ideal dibuat berdasarkan nilai default pada program STATISTICA 7. Hasil wajah Chernoff Provinsi Bali dan wajah Chernoff Ideal dapat dilihat pada Gambar 1. 


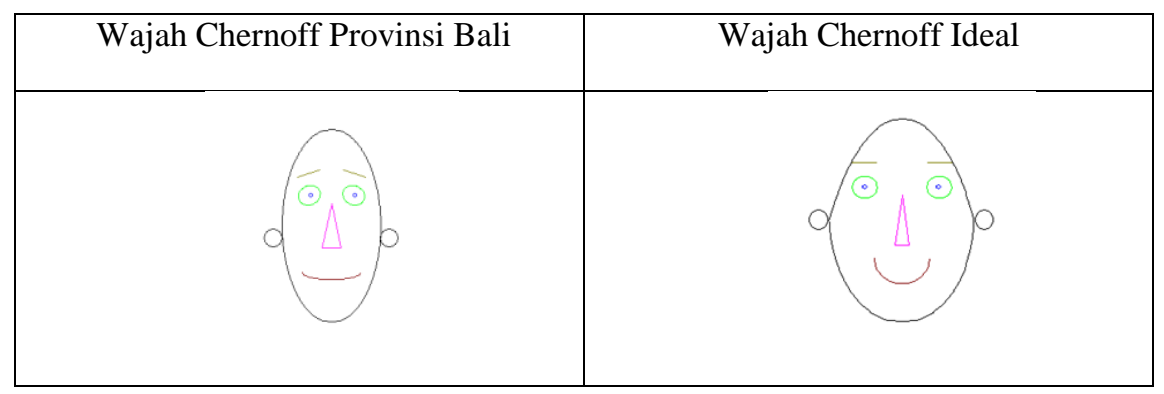

Gambar 1. Wajah Chernoff Provinsi Bali dan Wajah Chernoff Ideal

Proses perbandingan bertujuan untuk melihat ciri wajah yang kurang bagus dari Provinsi Bali. Ini bertujuan untuk melihat indikator kesejahteraan apa saja yang masih kurang baik di Provinsi Bali secara keseluruhan.

Dilihat dari Gambar 1, ciri wajah yang kurang baik dari wajah Chernoff Provinsi Bali antara lain : lebar wajah, posisi telinga, bentuk elips bawah wajah, panjang hidung, kelengkungan mulut, jarak antar mata, kemiringan mata dan kemiringan alis mata.

Berdasarkan pembahasan terdahulu, dari 18 indikator kesejahteraan rakyat untuk Provinsi Bali, 8 diantaranya masih kurang bagus.

Hasil wajah Chernoff untuk masing-masing kabupaten di Provinsi Bali dapat dilihat pada Gambar 2.

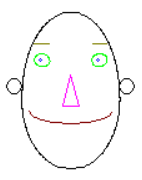

Tabanan

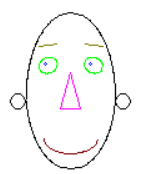

Gianyar

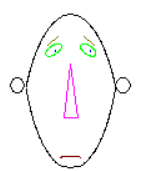

Karangasem
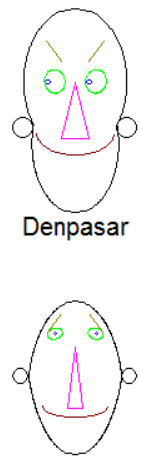

Klungkung

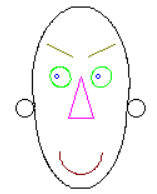

Badung

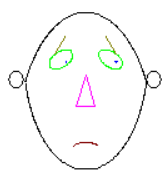

Bangli

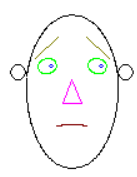

Jembrana

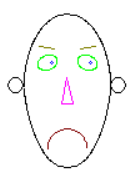

Buleleng

Gambar 2. Wajah Chernoff Masing-Masing Kabupaten di Provinsi Bali

Berdasarkan Gambar 2, Kabupaten Tabanan merupakan kabupaten yang paling sejahtera dan Kabupaten Karangasem merupakan kabupaten yang kurang sejahtera di Provinsi Bali. 


\section{Kesimpulan}

Berdasarkan hasil dan pembahasan dalam penelitian ini, maka dapat disimpulkan bahwa dari 18 indikator kesejahteraan rakyat untuk Provinsi Bali, 8 diantaranya masih kurang bagus yaitu jumlah pengangguran terbuka, kepadatan penduduk per $\mathrm{km}^{2}$, angka harapan hidup, pendapatan per kapita, persentase rumah tangga dengan jenis lantai bukan tanah, persentase rumah tangga dengan luas lantai $<20 \mathrm{~m}^{2}$, persentase rumah tangga dengan fasilitas BAB sendiri dan penduduk yang bekerja. Lebih lanjut lagi, berdasarkan hasil wajah Chernoff untuk masing-masing kabupaten di Provinsi Bali, terlihat bahwa Kabupaten Tabanan merupakan kabupaten yang paling sejahtera dan Kabupaten Karangasem merupakan kabupaten yang paling kurang sejahtera di Provinsi Bali.

\section{Daftar Pustaka}

[1] BPS. 2011. Bali Dalam Angka 2011. Bali: BPS Provinsi Bali

[2] BPS. 2011. Indikator Kesejahteraan Rakyat Provinsi DKI Jakarta. Jakarta: BPS Provinsi Jakarta

[3] Johnson, R.A., dan Winchern, D.W. 2002. Applied Multivariate Statistical Analysis, 5th ed. New Jersey: Prentice Hall International Inc.

[4] Tickle, Naomi R. 2012. Cara Cepat Membaca Wajah Menjadi Seseorang yang Paling Diinginkan dan Menyenangkan. Jakarta: Ufuk Press 